\title{
OBSTETRICS
}

\section{Fetal programming and systemic sclerosis}

\author{
Gianpaolo Donzelli, MD, PhD; Giulia Carnesecchi, MD; Carolina Amador, MD, PhD; \\ Mariarosaria di Tommaso, MD, PhD; Luca Filippi, MD; Roberto Caporali, MD; \\ Veronica Codullo, MD, PhD; Valeria Riccieri, MD; Guido Valesini, MD; \\ Armando Gabrielli, MD; Roberta Bagnati, MD; Kathleen S. McGreevy, PhD; \\ Salvatore De Masi, MD; Marco Matucci Cerinic, MD, PhD
}

\section{OBJECTIVE: This study investigated whether birthweight is linked to an increased risk of the development of systemic sclerosis.}

STUDY DESIGN: This was a multicenter case-control study with perinatal data that were obtained from 332 cases with systemic sclerosis and 243 control subjects. Birthweight was treated as a dichotomous variable ( $<2500 \mathrm{~g}$ vs $\geq 2500 \mathrm{~g}$ ); low birthweight was defined as a weight $<2500 \mathrm{~g}$; small for gestational age was defined as birthweight $<10$ th percentile for gestational age adjusted for sex. The relationship between systemic sclerosis and both low birthweight and small for gestational age was expressed with the crude (univariate analysis) and adjusted (multivariate analysis) odds ratio (OR).
RESULTS: Significantly increased ORs were observed in the univariate analysis for low birthweight $(\mathrm{OR}, 2.59 ; 95 \%$ confidence interval $[\mathrm{Cl}]$, $1.39-5.05)$ and small for gestational age $(\mathrm{OR}, 2.60 ; 95 \% \mathrm{Cl}$, 1.34-5.32) subjects. Similarly increased risks were confirmed for both conditions in the multivariate analysis $(\mathrm{OR}, 3.93 ; 95 \% \mathrm{Cl}$, $1.92-8.07$; and $\mathrm{OR}, 2.58 ; 95 \% \mathrm{Cl}, 1.28-5.19$ ), respectively.

CONCLUSION: Low birthweight and small for gestational age at birth are risk factors for the adult onset of systemic sclerosis.

Key words: autoimmune disease, birthweight, epigenetics, fetal programming, scleroderma

Cite this article as: Donzelli G, Carnesecchi G, Amador C, et al. Fetal programming and systemic sclerosis. Am J 0bstet Gynecol 2015;213:839.e1-8.

S ystemic sclerosis (SSc), also known as scleroderma, is a chronic autoimmune disease characterized by vascular obliteration, excessive extracellular matrix deposition, and fibrosis of the connective tissues. ${ }^{1,2}$ Estimates of the disease's prevalence and incidence range from 50-300 cases per million people and $2.3-22.8$ cases per million people per year, respectively. ${ }^{3}$ Women are more likely to experience SSc than are men, with reported ratios ranging from $3: 1-14: 1$; a slightly increased susceptibility has also been reported among black patients. ${ }^{4}$
The cause of SSc has remained elusive despite intense investigation, although there is convincing evidence that genetic factors contribute to its onset and development. Genetics studies suggest that SSc is a complex polygenic disease. Candidate gene studies have identified critical immunoregulatory genes and gene regions (in particular, the human leukocyte antigen region) as susceptibility genes for the development of the disease. ${ }^{5}$ However, even though the genetic contribution to the disease has been shown, it now seems that environmental agents also play a critical role. ${ }^{6}$ The link between

From the Department of Fetal-Neonatal Medicine (Drs Donzelli, Amador, Filippi, and De Masi) and the Research, Innovation, and International Relations Office (Dr McGreevy), Meyer Children's Hospital, and Departments of Experimental and Clinical Medicine (Drs Carnesecchi and Matucci Cerinic) and Health Sciences (Dr di Tommaso), University of Florence, Florence; Department of Rheumatology, University and IRCCS Foundation, Policlinico San Matteo, Pavia (Drs Caporali and Codullo); Department of Internal Medicine and Clinical Specialties, Rheumatology Unit, "La Sapienza" University, Rome (Drs Riccieri and Valesini); and Institute of General Clinical Medicine, Hematology, and Clinical Immunology, University of Ancona, Ancona (Drs Gabrielli and Bagnati), Italy.

Received Oct. 9, 2014; revised June 16, 2015; accepted July 21, 2015.

The authors report no conflict of interest.

Corresponding author: Gianpaolo Donzelli, MD, PhD. gianpaolo.donzelli@unifi.it

0002-9378/\$36.00 • ๑ 2015 Elsevier Inc. All rights reserved. • http://dx.doi.org/10.1016/j.ajog.2015.07.034

genes and environment is represented by the new field of research of epigenetics: the study of heritable changes in genes and gene expression that do not involve DNA nucleotide sequences. Epigenetic modifications include DNA methylation, histone modifications, and microRNA expression. ${ }^{7}$ In humans, cytosine methylation and its modifications in response to maternal diet is 1 of the most widely studied epigenetic modifications and is a sign of adverse exposure in utero. Interestingly, differentially methylated regions that are dependent on the mother's diet have been identified in the liver of female offspring, which represents potential marks of developmental programming that may link the intrauterine environment to metabolic health later in life. ${ }^{8}$

This is an epidemiologic study that was inspired by the robust work of David Barker ${ }^{9}$ and others, who postulated that the environment can modify the developmental trajectory of an individual even during the first stages of life, thus laying the foundations for disease in adulthood (the so-called fetal programming theory). In fact, it is possible that adverse environmental conditions during 
fetal growth could alter developmental processes and explain how a single genotype can give rise to different phenotypes (developmental plasticity). ${ }^{10}$ This approach has been shown to be valid particularly for chronic diseases such as cardiovascular disease, ${ }^{11}$ metabolic diseases (including diabetes mellitus), ${ }^{12}$ osteoporosis, and some forms of cancer. ${ }^{13}$ In line with this theory, several studies have shown that low birthweight (LBW), which can be indicative of exposure to an adverse fetal environment during specific stages of gestation (socalled "critical" periods, when rapid cell division takes place), led to an increased risk of chronic diseases in adulthood because of programming of the neuroendocrine setting, antioxidant defenses, inflammation, and the immune system itself. $^{14,15}$

This study was based on the hypothesis that the immune system is subject to developmental plasticity during its maturation, with a real possibility that disruptors in the early fetal environment may impair its function by epigenetic mechanisms, thereby increasing the onset of chronic autoimmune diseases. ${ }^{16,17}$ The main goal was to evaluate whether a significant correlation exists between birthweight and/or gestational age and the subsequent development of SSc.

\section{Materials and Methods}

A multicenter case-control study was conducted from June 2012 to November 2013; 332 consecutive prevalent cases of SSc were enrolled from the rheumatologic outpatient clinics of the following hospitals: Careggi University Hospital of Florence, La Sapienza University Hospital of Rome, the IRCCS Foundation and San Matteo University Hospital of Pavia, and the University Hospital of Ancona. The study was approved by the Ethics Committee of the Meyer Children's Hospital, University of Florence. Cases were defined as patients affected by SSc according to the recent classification developed by the American College of Rheumatology/European League. ${ }^{18}$ Two hundred forty-three consecutive control subjects were recruited from the surgical outpatient clinic of the Careggi University Hospital of Florence during the same period. Control subjects were matched to cases with the use of a frequency-matching method to obtain a similar age/sex distribution in both groups.

To collect demographic and perinatal information, a standardized questionnaire was created, and the patients were interviewed by trained medical personnel. The following information was collected: patient identification, sex, age, birthweight, gestational age at birth, their mother's age at birth, whether they were breastfed, and the mother's smoking habit. Birthweight and gestational age were recorded as continuous variables; when subjects did not recall exact values, they were asked to categorize birthweight as <2500, 2500-3999, or $\geq 4000 \mathrm{~g}$ and gestational age as $<37$, $37-41$, or $>41$ weeks. With regard to the occupational histories of patients and control subjects, particular attention was given to exposure to crystalline silica, organic solvents, welding fumes, epoxy resins, and pesticides. ${ }^{19}$ To minimize recall bias and ensure the validity of the approach, the data that were collected were compared with the data recorded in the clinical charts, even if this was possible only in 40 of the patients (12\%) and 24 of the control subjects $(10 \%)$ because of a lack of available records, especially in the case of older subjects. Moreover, the interview was repeated 1 month later in a randomized group of 40 patients and 40 control subjects to assess the level of uncertainty that had been attributed to recall.

The following disease characteristics were obtained directly from the hospital databases for all patients with a diagnosis of SSc: auto-antibody pattern (antinuclear antibodies, anticentromere antibodies, anti-Scl-70), age at disease onset, type of disease (diffuse cutaneous, limited cutaneous), organ involvement (articular, cardiac, gastrointestinal, pulmonary), and the presence of pulmonary hypertension and digital ulceration. The exclusion criteria for both patients and control subjects were refusal to participate, the presence of chronic diseases (such as coronary heart disease and related disorders, stroke, hypertension, and type 2 diabetes mellitus ${ }^{14}$ ), and occupation-related SSc risk factors (in particular organic solvents, silica, white spirit, welding fumes, and epoxy resins). ${ }^{19}$ Furthermore, the presence of other autoimmune diseases was an exclusion criterion for patients with SSc; the presence of any autoimmune disease was an exclusion criterion for control subjects. The Regional Center of Rare Diseases of the Meyer Children's Hospital, University of Florence, developed the research protocol, supervised the data collection and performed the statistical data analysis.

$L B W$ was defined as a weight at birth of $<2500 \mathrm{~g}$, as per the International Statistical Classification of Diseases and Related Health Problems, 10th revision. The term small for gestational age (SGA) refers to infants whose birthweights and/ or lengths are at least 2 standard deviation units less than the mean for gestational age. ${ }^{20}$ In clinical practice, SGA commonly is defined as a birthweight $<10$ th percentile for gestational age and sex relative to the population standard; it is used as a measurable proxy for intrauterine growth restriction and later health risks. ${ }^{21}$

The study population was divided according to birthweight $(<2500$, $\geq 2500$, or $\geq 4000 \mathrm{~g}$ ) and gestational age (preterm, <37 weeks; at term, 37-41 weeks; postterm, $>41$ weeks). The association between LBW and SSc and between SGA and SSc was expressed with the odds ratio (OR) calculated with a univariate analysis that considered 2 birthweight groups ( $<2500$ and $\geq 2500$ g). Two multivariate analyses were then performed to test the associations among all 3 birthweight groups $(<2500$, 2500-3999, and $\geq 4000 \mathrm{~g}$ ) and both SGA conditions, with the risks for SSc adjusted for other confounding factors. A sample size of 318 cases and 212 control subjects was estimated, with the assumption of a $5 \%$ exposure among control subjects and a minimum appreciable OR of 3 (alpha error, 5\%; power, $90 \%)$. The statistical analysis was performed with the Stata software (version 10; StataCorp LP, College Station, TX). Eleven percent of the subjects in both groups (66/575) were excluded because of uncertainty about their 
birthweight (15.4\% of case studies and $6.2 \%$ of control subjects); the gestational age was uncertain in $4.5 \%$ of case studies and $0.0 \%$ of the control group.

\section{Results}

The clinical characteristics of the study population are presented in Table 1 . The expected sex distribution of disease and frequency matching that was adopted for the enrolled control subjects demonstrated a high prevalence of female cases in the study population compared with male cases. The age comparison between case studies and control subjects showed that the mean age of patients with SSc was slightly higher in the control group. Mothers of patients with SSc were slightly older than the control subjects at the time of delivery.

It was observed that LBW and SGA were more prevalent in subjects with SSc than in the control subjects $(13.9 \%$ vs $6.9 \%$ and $12.0 \%$ vs $5.8 \%$, respectively), with a less pronounced difference regarding preterm births $(2.7 \%$ vs $1.6 \%)$. Table 2 contains the ORs of SSc that were evaluated as a univariate analysis for LBW, SGA, maternal age at delivery, gestational age, breastfeeding, and the mother's smoking behavior during pregnancy. SSc was more prevalent in LBW infants than in non-LBW infants (OR, 2.59; 95\% confidence interval $[\mathrm{CI}], 1.39-5.05)$. When the analysis was limited to female subjects only, the OR rose to $2.90 \quad(95 \% \mathrm{CI}$, 1.51-5.89). A similar result was found when exposure to SGA was considered (OR, 2.60; 95\% CI, 1.34-5.32, increasing to $\mathrm{OR}, 2.73 ; 95 \% \mathrm{CI}$, $1.38-5.73$ in female subjects). Both estimated risks were statistically significant $(P<.05)$. The results showed that advanced maternal age ( $>34$ years) was associated with an increased risk of SSc (OR, 2.28; 95\% CI, 1.34-3.88). The mother's age at the time of delivery therefore can be considered an additional, independent risk factor for the disease. Conversely, the breastfeeding and smoking habits of the mothers of patients with SSc were not associated with a significantly increased risk of SSc.

Table 3 shows the multivariate analysis limited to female subjects that,

\section{TABLE 1 \\ Study population}

\begin{tabular}{|c|c|c|c|c|}
\hline Variable & $\begin{array}{l}\text { Cases } \\
(n=332)\end{array}$ & $\begin{array}{l}\text { Control } \\
\text { subjects } \\
(n=243)\end{array}$ & $P$ value & $\begin{array}{l}\text { Total } \\
(\mathrm{n}=575)\end{array}$ \\
\hline Mean age, $y \pm S D$ & $59.1 \pm 13.2$ & $56.1 \pm 6.2$ & $<.05$ & $58.1 \pm 11.5$ \\
\hline Maternal age at delivery, $\mathrm{y} \pm \mathrm{SD}$ & $29.3 \pm 6.0$ & $27.9 \pm 5.8$ & $<.05$ & $28.7 \pm 5.9$ \\
\hline Sex, n (\%) & & & .07 & \\
\hline Male & $15(4.5)$ & $18(7.4)$ & & $33(5.7)$ \\
\hline Female & $317(95.5)$ & $225(92.6)$ & & $542(94.3)$ \\
\hline Birthweight, n (\%) & & & $<.05$ & \\
\hline Missing & $51(15.4)$ & $15(6.2)$ & & $66(11.5)$ \\
\hline$<2500 \mathrm{~g}$ & $46(13.9)$ & $16(6.6)$ & & $62(10.8)$ \\
\hline$\geq 2500 \mathrm{~g}$ & $235(70.8)$ & $212(87.2)$ & & $447(77.7)$ \\
\hline Gestational age at birth, $\mathrm{n}(\%)$ & & & .66 & \\
\hline Missing & $15(4.5)$ & $2(0.9)$ & & $15(2.6)$ \\
\hline Preterm & $9(2.7)$ & $4(1.6)$ & & $13(2.3)$ \\
\hline Term & $299(90.1)$ & $230(94.6)$ & & $531(92.3)$ \\
\hline Postterm & $9(2.7)$ & $7(2.9)$ & & $16(2.8)$ \\
\hline Small for gestational age, $\mathrm{n}(\%)$ & & & $<.05$ & \\
\hline Missing & $57(17.2)$ & $15(6.2)$ & & $72(12.5)$ \\
\hline Yes & $40(12.0)$ & $14(5.8)$ & & $54(9.4)$ \\
\hline No & $235(70.8)$ & $214(88.1)$ & & $449(78.1)$ \\
\hline Breastfeeding, n (\%) & & & .41 & \\
\hline Missing & $108(32.5)$ & $4(1.7)$ & & $112(19.5)$ \\
\hline Yes & $202(60.8)$ & $217(89.3)$ & & $419(72.9)$ \\
\hline No & $22(6.7)$ & $22(9.0)$ & & $44(7.6)$ \\
\hline Mother's smoking habit, n (\%) & & & .29 & \\
\hline Missing & $107(32.2)$ & $7(2.9)$ & & $114(19.8)$ \\
\hline Yes & $9(2.7)$ & $12(4.9)$ & & $21(3.6)$ \\
\hline No & $216(65.1)$ & $224(92.2)$ & & $440(76.5)$ \\
\hline
\end{tabular}

Disease subtype, $\mathrm{n}(\%)$

\begin{tabular}{lc}
\hline Missing & $13(3.9)$ \\
\hline $\begin{array}{l}\text { Limited cutaneous systemic } \\
\text { sclerosis }\end{array}$ & $246(74.1)$ \\
\hline
\end{tabular}

Diffuse cutaneous systemic $73(22.0)$

sclerosis

Antibodies, n (\%)

\begin{tabular}{cc}
\hline Missing & $96(28.9)$ \\
\hline Anticentromere antibodies & $133(40.1)$ \\
\hline Scl70 & $100(30.1)$
\end{tabular}

Anticentromere antibodies + Scl70 $3(0.9)$ (topoisomerase I)

Donzelli. Developmental origins of systemic sclerosis. Am J Obstet Gynecol 2015. 


\section{TABLE 2}

\section{Odds ratio of systemic sclerosis: univariate analysis}

\begin{tabular}{lccc} 
Variable & Cases, $\mathbf{n} \begin{array}{l}\text { Control } \\
\text { subjects, } \mathbf{n}\end{array}$ & $\begin{array}{l}\text { Odds ratio (95\% } \\
\text { confidence interval) }\end{array}$ \\
\hline Birthweight, g & 46 & 16 & $2.59(1.39-5.05)$ \\
\hline$<2500$ & 235 & 212 & 1.00 \\
\hline$\geq 2500$ & & & \\
\hline Birthweight (female only), g & 46 & 14 & $2.90(1.51-5.89)$ \\
\hline$<2500$ & 224 & 198 & 1.00 \\
\hline$\geq 2500$ & & & \\
\hline Small for gestational age & 40 & 14 & $2.60(1.34-5.32)$ \\
\hline Yes & 235 & 214 & 1.00 \\
\hline No & & & \\
\hline Small for gestational age (female only) & 40 & 13 & $2.73(1.38-5.73)$ \\
\hline Yes & 224 & 199 & 1.00 \\
\hline No & &
\end{tabular}

Maternal age at delivery (female only), y

\begin{tabular}{|c|c|c|c|}
\hline$<25$ & 69 & 68 & 1.00 \\
\hline $25-29$ & 100 & 79 & $1.25(0.80-1.95)$ \\
\hline $30-34$ & 74 & 46 & $1.58(0.96-2.61)$ \\
\hline$>34$ & 74 & 32 & $2.28(1.34-3.88)$ \\
\hline
\end{tabular}

\begin{tabular}{lrrrr}
\hline Gestational age (female only), wk & & & \\
\hline $37-41$ & 284 & 213 & 1.0 \\
\hline$<37$ & 9 & 3 & $2.28(0.61-8.53)$ \\
\hline$>41$ & 9 & 6 & $1.14(0.40-3.25)$ \\
\hline
\end{tabular}

\section{Breastfeeding}

\begin{tabular}{lrrr}
\hline Yes & 202 & 217 & $0.93(0.50-1.73)$ \\
\hline No & 22 & 22 & 1.0 \\
\hline Yeastfeeding (female only) & & & \\
\hline Yes & 189 & 202 & $1.07(0.54-2.14)$ \\
\hline No & 20 & 23 & 1.0
\end{tabular}

\section{Mother's smoking habit}

\begin{tabular}{lccc}
\hline Yes & 9 & 12 & $0.78(0.28-2.06)$ \\
\hline No & 216 & 224 & 1.0 \\
\hline Mother's smoking habit (female only) & & & \\
\hline Yes & 8 & 11 & $0.74(0.25-2.07)$ \\
\hline No & 203 & 207 & 1.0 \\
\hline
\end{tabular}

Donzelli. Developmental origins of systemic sclerosis. Am J Obstet Gynecol 2015.

through 2 different mathematical models, shows the independent effect of birthweight grouped into different classes: birthweight (overweight, $\geq 4000 \mathrm{~g}$; underweight, $<2500 \mathrm{~g}$; and normal weight, $2500-4000 \mathrm{~g}$ ), gestational age (term, preterm, and postterm), age of cases and control subjects, and maternal age at delivery. The multivariate analysis shows that the odds of disease in the female LBW group are approximately 4 times higher than in the normal birthweight group. No additional risk was observed in subjects with birthweight $>4000 \mathrm{~g}$ as compared with subjects of normal weight at birth (2500$3999 \mathrm{~g}$ ). SGA status increases the OR of disease approximately 2.6 -fold in the multivariate analysis that includes the age of cases and control subjects and maternal age at delivery. In both models, the patient's age is an independent risk factor for disease, with a risk of $4 \%$ (model 1) and 5\% (model 2) for each additional year (Table 3 ).

Table 4 shows several disease features that are related to LBW and SGA status. No correlation was found between LBW and SGA with the age at the onset of lung, gastrointestinal, articular, or cardiac involvement or the presence of ulcers and pulmonary hypertension in patients with SSc. Within the context of the high correlation between LBW and adult-onset SSc, there is an increased risk of the limited form compared with the diffuse form of the disease (OR, 0.36; 95\% CI, 0.10-0.97). The compliance between the questionnaire data and the data recorded in the clinical charts was high and did not differ between cases (93\%) and control subjects (95\%). Furthermore, the repetition of the interview resulted in an accuracy of 95\%; 76 of 80 subjects reported exactly the same data in both interviews.

The incidence of missing data was always higher for cases than control subjects because of a lower percentage of survival of subjects' parents (an important source of information). Simulating a situation in which the missing data proved to be opposed to the study's primary hypothesis (LBW and SGA vs SSc), we attributed a high weight $(>2500 \mathrm{~g})$ to all patients of the case group with missing weight data and still obtained a statistically significant OR of 2.1.

\section{Comment}

The principal finding of the study was that LBW and SGA status represent risk factors for the development of SSc at an adult age, with a higher incidence for 
LBW. However, it is interesting to note that no additional risk was observed in subjects with high birthweight, in contrast with other epidemiologic studies that have demonstrated a significant correlation between a birthweight of $\geq 4000 \mathrm{~g}$ and adult-onset rheumatologic autoimmune diseases such as Sjogren's syndrome ${ }^{22}$ and rheumatoid arthritis. ${ }^{23,24}$ An increased risk was also observed for systemic lupus erythematosus for both high birthweight and premature birth. ${ }^{25}$ These findings seem to indicate that both conditions (LBW, $<2500 \mathrm{~g})$ and high birthweight $(\geq 4000$ g) may influence fetal developmental plasticity and result in a chronic autoimmune disease in adulthood.

From a clinical standpoint, this study allows LBW to be considered as an additional risk factor with respect to those already known for the development of SSc. ${ }^{19}$ It is clear that prematurity or intrauterine growth retardation are not limited to conditioning health in the short-term but can cause various diseases over the long-term, which include hypertension, diabetes mellitus, obesity, and heart disease; we can add SSc, which is part of the broader spectrum of autoimmune rheumatic diseases, to this list.

The mechanisms that link birthweight, gestational age, and autoimmune disease can be inserted in a growing body of evidence that highlights the importance of intrauterine insults in programming the developing immune system. An adverse intrauterine environment seems to cause thymus dysfunction and subsequent long-term immunologic deregulation, ${ }^{26}$ and it was significantly more likely to find incomplete thymus involution in SSc and patients with rheumatoid arthritis than in a nonautoimmune control group. ${ }^{27}$ Several studies have demonstrated that cesarean delivery, which often is associated with stressful intrauterine conditions, is linked to shortterm consequences for the newborn infant and increased risk of asthma, allergies, and type 1 diabetes mellitus in adulthood. ${ }^{28,29}$ Cesarean delivery seems to perturb the neonate's microbiome, and the lack of a labor-induced stress response negatively affects immune activation; these mechanisms lead to

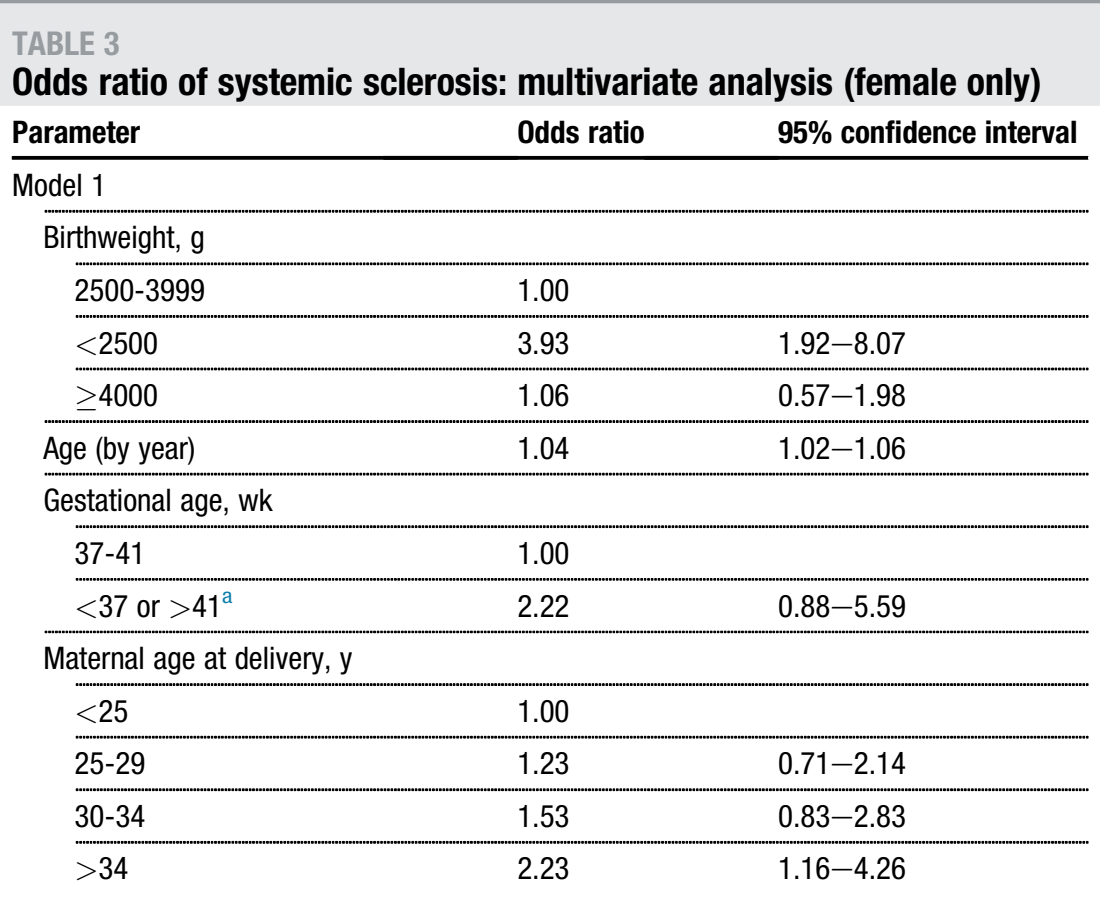

Model 2

Small for gestational age

\begin{tabular}{lcc}
\hline No & 1.00 & \\
\hline Yes & 2.58 & $1.28-5.19$ \\
\hline Age (by year) & 1.05 & $1.03-1.07$ \\
\hline Maternal age at delivery, $y$ & & \\
\hline$<25$ & 1.00 & $0.72-1.93$ \\
\hline $25-29$ & 1.18 & $0.84-2.56$ \\
\hline $30-34$ & 1.46 & $1.11-3.63$ \\
\hline$>34$ & 2.01 & \\
\hline
\end{tabular}

${ }^{\text {a }}$ Cases with gestational age $<37$ and $>41$ weeks were grouped together on the basis of the results of the univariate analysis (Table 2), which showed no statistical difference between each of these groups and the reference category.

Donzelli. Developmental origins of systemic sclerosis. Am J Obstet Gynecol 2015.

epigenetic changes and therefore a predisposition to immune-related disorders. $^{30}$ For example, DNA hypermethylation was found in hematopoietic stem cells of infants born by cesarean delivery at term. ${ }^{31}$ Another postulated programming mechanism involves activation of the maternal hypothalamicpituitary-adrenal axis (HPA) in response to nutritional stress with consequent high fetal exposure to glucocorticoids. This hormone elevation could give rise to an early shift from cell proliferation to cell differentiation in the immune system, with an inappropriate pattern of growth for the stage of development and possible adverse consequences much later in life. ${ }^{32,33}$ Altered HPA activity was reported to be a possible underlying mechanism in an animal model study that found a transgenerational effect of maternal treatment with dexamethasone, a common clinical practice in pregnancies at risk of preterm birth: first filial generation and second filial generation ewe lamb offspring showed an increased baseline but reduced stimulated HPA activity. ${ }^{34}$ Another pathway through which maternal nutrition has broad relevance for immune-mediated diseases is represented by the link between a lack of omega-3 fatty acids during pregnancy and the suppression of interleukin 13 


\section{TABLE 4}

\section{Odds ratio: female and cases only}

Odds ratio (95\% confidence interval)

\begin{tabular}{lll}
\cline { 2 - 3 } Variable & $\begin{array}{l}\text { Low birthweight/ } \\
\text { no low birthweight }\end{array}$ & $\begin{array}{l}\text { Small for gestational } \\
\text { age/no small for } \\
\text { gestational age }\end{array}$ \\
\hline Type of disease: systemic sclerosis & 1.0 & 1.0 \\
\hline Limited cutaneous & $0.36(0.10-0.97)$ & $0.43(0.12-1.18)$ \\
\hline Diffuse cutaneous & & \\
\hline
\end{tabular}

Age of disease onset, y

\begin{tabular}{lll}
\hline$<30$ & 1.0 & 1.0 \\
\hline $30-59$ & $1.68(0.61-4.58)$ & $1.81(0.60-5.47)$ \\
\hline$>59$ & $1.71(0.47-6.19)$ & $2.37(0.61-9.29)$ \\
\hline
\end{tabular}

Pulmonary hypertension

\begin{tabular}{lcc}
\hline No & 1.0 & 1.0 \\
\hline Yes & $1.22(0.34-3.68)$ & $1.54(0.42-4.73)$ \\
\hline Ulcers & & \\
\hline No & 1.0 & 1.0 \\
\hline Yes & $0.62(0.26-1.35)$ & $0.67(0.27-1.53)$ \\
\hline
\end{tabular}

Pulmonary involvement

\begin{tabular}{lcc}
\hline No & 1.0 & 1.0 \\
\hline Yes & $1.10(0.53-2.32)$ & $1.38(0.63-3.15)$ \\
\hline Gastrointestinal involvement & & \\
\hline No & 1.0 & 1.0 \\
\hline Yes & $1.53(0.69-3.59)$ & $1.67(0.71-4.25)$ \\
\hline
\end{tabular}

\section{Cardiac involvement}

\begin{tabular}{lll}
\hline No & 1.0 & 1.0 \\
\hline Yes & $1.53(0.15-8.67)$ & $1.84(0.17-10.52)$ \\
\hline
\end{tabular}

Articular involvement

\begin{tabular}{lll}
\hline No & 1.0 & 1.0 \\
\hline Yes & $0.56(0.24-1.23)$ & $0.61(0.25-1.39)$
\end{tabular}

Donzelli. Developmental origins of systemic sclerosis. Am J Obstet Gynecol 2015.

cytokine production, which seems to alter $\mathrm{T}$ helper cell 2 and 1 balance at birth with a pronounced $\mathrm{T}$ helper cell 2 deviation. This mechanism could be the basis for a predisposition to allergic diseases in adult life. ${ }^{35}$ In addition to nutritional shortage, early alterations to the immune system could also result from nutritional excesses; for example, regulators that are related to inflammatory and cytokine signaling were found to be activated significantly in obese women.
Furthermore, mother obesity seems to up-regulate genes that are implicated in the development of the hippocampus, cerebral cortex, and amygdala, which results in neurodegeneration and decreased survival of sensory neurons that might influence neurodevelopment. ${ }^{36}$ Entringer et $\mathrm{al}^{37}$ assessed leukocyte telomere length in cord blood peripheral cells and observed a significant, independent, linear effect of pregnancy-specific stress on newborn infant leukocyte telomere length. These findings indicate that psychologic stress during pregnancy may program the developing telomere biology system, which is 1 of the predictors of agerelated diseases and death.

There is persuasive evidence that supports a significant contribution of epigenetic dysregulation to the origin of SSc: environmental agents may conduce epigenetic modifications to genes that are involved in the immune system and therefore break tolerance, induce selfantigen abnormality, and finally trigger immune reactions. ${ }^{38}$ As proof of this, alterations in DNA methylation, histone code modifications, and changes in microRNA expression levels have been observed in different cell lines (fibroblasts, lymphocytes, and endothelial cells) of patients with SSc. ${ }^{39,40}$ One of the main recognized environmental risk factors for SSc remains exposure to silica, but other occupational factors ${ }^{19}$ and viral agents ${ }^{41}$ could also contribute to SSc pathogenesis. Finally, it is now wellknown that endothelial cell injury is an early event in SSc pathogenesis, and abnormal vasoreactivity is thought to result from endothelial cell malfunction, with an imbalance favoring vasoconstriction. ${ }^{42}$ Endothelial progenitor cells (EPCs) are immature cells that derive from bone marrow and proliferate, migrate, and home to sites of neovascularization, differentiating into mature endothelial cells in situ; EPCs play a critical role in vascular repair and new blood vessel formation. A recent study demonstrated that LBW preterm neonates show an alteration of EPC function with subsequent impaired angiogenic capacity as compared with full-term neonates. Furthermore, the angiogenic defect of LBW endothelial colony-forming cells was confirmed in mice by their inability to form robust capillary networks. ${ }^{43}$

Regarding the research implications of the study, further research is needed to clarify the pathogenic links that could explain the correlation between birthweight and the development of this autoimmune disease, in particular the mechanisms that result from a complex interplay among the factors of genetic susceptibility, environmental exposure, and epigenetic modifications. On the 
basis of the identification of specific epigenetic mechanisms, it would be possible to develop appropriate diagnostic and therapeutic strategies as part of a personalized/precision medicine approach that would improve the clinical outcome of patients with SSc.

This is the first study that has aimed to find a link between SSc and early life events in the context of epigenetics. Although the study has the strength of having been conducted with a large enrolled study population, the potential existence of several inaccuracies in the data collected cannot be ruled out, because they come from a cohort of births in the 1950s. However, the inaccuracies of this study were attenuated by a cross-check of the interview responses with perinatal data in clinical charts and the performance of a repeat interview, which are methods that have been validated in other studies. ${ }^{44-46}$

There is extensive evidence that subjects with LBW are at a greater risk of the development of many uncommunicable, chronic adult diseases. The results described here show a strong association between LBW and adult-onset of SSc.

\section{REFERENCES}

1. Medsger TA. Systemic sclerosis (scleroderma): clinical aspects. In: Koopman WJ, ed. Arthritis and allied conditions: a textbook of rheumatology. Philadelphia: Williams \& Wilkins; 1997:1433-65.

2. Gabrielli A, Avvedimento EV, Krieg T. Scleroderma. N Engl J Med 2009;360:1989-2003.

3. Chifflot H, Fautzi B, Sordet C, Chatelus E, Sibilia J. Incidence and prevalence of systemic sclerosis: a systematic literature review. Semin Arthritis Rheum 2008;37:223-35.

4. Helmick CG, Felson DT, Lawrence RC, et al. Estimates of the prevalence of arthritis and other rheumatic conditions in the United States; part I. Arthritis Rheum 2008;58:15-25.

5. Agarwal SK. The genetics of systemic sclerosis. Discov Med 2010;10:134-43.

6. Varga J, Abraham D. Systemic sclerosis: a prototypic multisystem fibrotic disorder. J Clin Invest 2007;117:557-67.

7. Godfrey KM, Barker DJ. Fetal programming and adult health. Public Health Nutr 2001;4: 611-24.

8. Heo H, Tozour J, Delahaye F, Zhao Y, Barzilai N, Einstein F. Differentially methylated regions as targets of adverse intrauterine environment. Am J Obstet Gynecol 2014; 210(suppl):S394.
9. Barker DJ. The developmental origins of chronic adult disease. Acta Paediatr Suppl 2004;93:26-33.

10. Moczek AP, Sultan S, Foster $S$, et al. The role of developmental plasticity in evolutionary innovation. Proc Biol Sci 2011;278:2705-13.

11. Seet E, Yee J, Ross M, Desai M. Programmed adipogenesis and obesity in offspring of obese dams. Am J Obstet Gynecol 2014;210(suppl):S33.

12. Cho GJ, Hong H-R, Hong S-C, Oh M-J, Kim HJ. Maternal smoke during pregnancy programs for bone disturbance in offspring. Am J Obstet Gynecol 2014;210(suppl):S51.

13. Liu Y, Hoyo C, Murphy S, et al. DNA methylation at imprint regulatory regions in preterm birth and infection. Am J Obstet Gynecol 2013;208:395.e1-7.

14. Barker DJ. Developmental origins of chronic disease. Public Health 2012;126:185-9.

15. Gluckman PD, Hanson MA, Cooper C, Thornburg KL. Effect of in utero and early-life conditions on adult health and disease. N Engl J Med 2008;359:61-73.

16. Costenbader KH, Gay S, AlarcónRiquelme ME, laccarino L, Doria A. Genes, epigenetic regulation and environmental factors: which is the most relevant in developing autoimmune diseases? Autoimmun Rev 2012;11: 604-9.

17. Lu Q. The critical importance of epigenetics in autoimmunity. J Autoimmun 2013;41:1-5.

18. Van den Hoogen F, Khanna D, Fransen J, et al. 2013 classification criteria for systemic sclerosis: an American college of rheumatology/ European league against rheumatism collaborative initiative. Ann Rheum Dis 2013;72: 1747-55.

19. Marie I, Gehanno JF, Bubenheim M, et al. Prospective study to evaluate the association between systemic sclerosis and occupational exposure and review of the literature. Autoimmun Rev 2014;13:151-6.

20. Lee PA, Chernausek SD, HokkenKoelega AC, Czernichow P. International Small for Gestational Age Advisory Board consensus development conference statement: management of short children born small for gestational age, April 24-October 1, 2001. Pediatrics 2003;111:1253-61.

21. Katz J, Wu LA, Mullany LC, et al. Prevalence of small-for-gestational-age and its mortality risk varies by choice of birth-weight-for-gestation reference population. PLoS One 2014;9: e92074.

22. Mostafavi B, Akyuz S, Jacobsson ME, Nilsen LV, Theander E, Jacobsson LH. Perinatal characteristics and risk of developing primary Sjögren's syndrome: a case-control study. J Rheumatol 2005;32:665-8.

23. Jacobsson LT, Jacobsson ME, Askling J, Knowler WC. Perinatal characteristics and risk of rheumatoid arthritis. BMJ 2003;326: 1068-9.

24. Mandl LA, Costenbader KH, Simard JF, Karlson EW. Is birthweight associated with risk of rheumatoid arthritis? Data from a large cohort study. Ann Rheum Dis 2009;68:514-8.

25. Simard JF, Karlson EW, Costenbader KH, et al. Perinatal factors and adult-onset lupus, Arthritis Rheum 2008;59:1155-61.

26. Ferri $C$, Colaci $M$, Battolla L, Giuggioli $D$, Sebastiani M. Thymus alterations and systemic sclerosis. Rheumatology (Oxford) 2006;45: 72-5.

27. Meunier M, Bazeli R, Feydy A, Drape JL, Kahan A, Allanore Y. Incomplete thymic involution in systemic sclerosis and rheumatoid arthritis. Joint Bone Spine 2013;80:48-51.

28. Cho CE, Norman M. Cesarean section and development of the immune system in theoffspring. Am J Obstet Gynecol 2013;208:249-54. 29. Cho CE, Norman M. Reply. Am J Obstet Gynecol 2013;209:496-7.

30. Romero R, Korzeniewski SJ. Are infants born by elective cesarean delivery without labor at risk for developing immune disorders later in life? Am J Obstet Gynecol 2013;208: 243-6.

31. Almgren M, Schlinzig T, Gomez-Cabrero D, et al. Cesarean delivery and hematopoietic stem cell epigenetics in the newborn infant: implications for future health? Am J Obstet Gyneco 2014;211:502.e1-8.

32. Cottrell EC, Holmes MC, Livingstone DE, Kenyon CJ, Seckl JR. Reconciling the nutritional and glucocorticoid hypotheses of foetal programming. FASEB J 2012;26:1866-74.

33. Moisiadis VG, Matthews SG. Glucocorticoids and fetal programming; part 1: outcomes. Nat Rev Endocrinol 2014;10:391-402.

34. Long NM, Ford SP, Nathanielsz PW. Multigenerational effects of fetal dexamethasone exposure on the hypothalamic-pituitary-adrena axis of first- and second-generation female offspring. Am J Obstet Gynecol 2013;208:217. e1-8.

35. Romero VC, Somers EC, Stolberg V, et al. Developmental programming for allergy: a secondary analysis of the Mothers, Omega-3, and Mental Health Study. Am J Obstet Gynecol 2013;208:316.e1-6.

36. Edlow A, Hui L, Wick H, Bianchi D. Term fetuses of obese women show gene expression consistent with neurodegeneration and metabolic dysregulation. Am J Obstet Gynecol 2014;210(suppl):S66.

37. Entringer S, Epel ES, Lin J, et al. Maternal psychosocial stress during pregnancy is associated with newborn leukocyte telomere length. Am J Obstet Gynecol 2013;208:134.e1-7.

38. Luo $Y$, Wang $Y$, Wang $Q$, Xiao $R$, Lu $Q$. Systemic sclerosis: genetics and epigenetics. J Autoimmun 2013;41:161-7.

39. Altorok N, Almeshal N, Wang Y, Kahaleh B. Epigenetics, the holy grail in the pathogenesis of systemic sclerosis. Rheumatology (Oxford) 2014 [Epub ahead of print].

40. Greer JM, McCombe PA. The role of epigenetic mechanisms and processes in autoimmune disorders. Biologics 2012;6: 307-27. 
41. Moroncini G, Mori S, Tonnini C, Gabrielli A. Role of viral infections in the etiopathogenesis of systemic sclerosis. Clin Exp Rheumatol 2013:31:3-7.

42. Matucci-Cerinic M, Kahaleh B, Wigley FM Review: evidence that systemic sclerosis is a vascular disease. Arthritis Rheum 2013;65:1953-62. 43. Ligi I, Simoncini S, Tellier E, et al. A switch toward angiostatic gene expression impairs the angiogenic properties of endothelial progenitor cells in low birth weight preterm infants. Blood 2011;118:1699-709.

44. Lucia VC, Luo Z, Gardiner JC, Paneth N, Breslau N. Reports of birthweight by adolescents and their mothers: comparing accuracy and identifying correlates. Paediatr Perinat Epidemiol 2006;20: 520-7.
45. Sanderson M, Williams MA, White E, et al, Validity and reliability of subject and mother reporting of perinatal factors. Am J Epidemiol 1998;147:136-40.

46. Natland ST, Andersen LF, Nilsen TI, Forsmo S, Jacobsen GW. Maternal recall of breastfeeding duration twenty years after delivery. BMC Med Res Methodol 2012;12:179. 